\title{
Effects of a Cognitive-Behavioral Oriented Awareness Program on Depression Levels of Obese Individuals
}

\author{
Gülay Oğuz'1, Müge Yılmaz², Saime Çağlı ${ }^{3}$, F. Mükerrem Güven4, M. Zihni Sungur ${ }^{5}$ \\ ${ }^{1}$ Department of Psychology, Canik Basari University, Samsun, Turkey \\ ${ }^{2}$ Department of Psychological Counselling and Guidance, Canik Basari University, Samsun, Turkey \\ ${ }^{3}$ Simurg Educational Consulting Firm, Samsun, Turkey \\ ${ }^{4}$ Alcohol and Substance Dependency Research and Practice Center, Akdeniz University, Antalya, Turkey \\ ${ }^{5}$ Department of Psychiatry, Faculty of Medicine, Marmara University, İstanbul, Turkey \\ Email: gozdemir24@hotmail.com
}

Received 12 June 2014; revised 14 July 2014; accepted 26 August 2014

Copyright (C) 2014 by authors and OALib.

This work is licensed under the Creative Commons Attribution International License (CC BY).

http://creativecommons.org/licenses/by/4.0/

(c) (i) Open Access

\begin{abstract}
The aim of this study was to investigate the effects of the cognitive-behavioral oriented awareness program on depression levels of obese individuals. Both the experimental and control group included 20 individuals. A pre and post-test research model was used in this study. Beck Depression Inventory (BDI) was the scale applied to both of the study groups. Mann-Whitney $U$ test and Wilcoxon signed-rank test were used to find out if meaningful differences emerged between the pre-test and post-test scores of control and experimental group. It was found that this awareness program had positive effects on BDI scores. Post test scores showed significant difference between the experimental and the control groups. No significant difference was found between pre and post-test BDI scores in the control group. The findings are discussed irrelevance to available literature, and some suggestions have been made regarding using the Awareness Program to reduce depression in obese individuals.
\end{abstract}

\section{Keywords}

Awareness Program, Cognitive-Behavioral Approach, Obesity, Depression

Subject Areas: Psychiatry \& Psychology, Public Health

\section{Introduction}

Obesity has recently been one of the most important health problems in both developed and developing coun-

How to cite this paper: Oğuz, G., Yılmaz, M., Çağlı, S., Güven, F.M. and Sungur, M.Z. (2014) Effects of a Cognitive-Behavioral Oriented Awareness Program on Depression Levels of Obese Individuals. Open Access Library Journal, 1: e905.

http://dx.doi.org/10.4236/oalib.1100905 
tries [1]. Obesity is a result of an increase in the ratio between the fatty and the fatless mass and considering the height, the rise of the weight beyond desired levels. $15 \%-18 \%$ of adult males and $20 \%-25 \%$ of adult females consist of fat tissues (exceeding 25\% for males and 30\% for females mean obesity). Obesity is diagnosed via Body Mass Index (BMI). While BMI level between 20 - $25 \mathrm{~kg} / \mathrm{m}$ are considered to be healthy, the ones between 25 - 29.9 are considered to be overweight, and BMI 30 and over are considered to be obese [2]. Obesity causes organic diseases like hypertension, hyperlipidemia, and diabetes mellitus; there are also studies that show that obese individuals are much more prone to psychological anomalies and depression [3] [4]. It was seen that the relationship between depression and obesity are much stronger in females than males [5].

In addition to genetic tendency, cultural, social, and emotional factors related to diet play a role in obesity [2]. According to DSM-IV-TR classification, obesity does not take place in eating disorders [6]. But obesity has the psychological signs that are seen in eating disorders. These features are attentional impulsivity, low self esteem, disliking his/her body shape, perfectionist attitude and (not to control the attitudes) [7] [8]. In obesity treatment there are various treatment types in order to losing weight. These are diets, physical exercise programs, pharmacological treatments, surgical operations and Cognitive-Behavioral therapies. Cognitive-behavioral approach is one of the most popular ones which are used to help obese individuals. Cognitive-Behavioral Therapies require collective effort and cooperation of the therapist and the patient. In this respect, cognitive therapies like behavioral therapies are not the process that are done to the patient, but the ones that are done together with the patient. First the problems are lined up, and they are studied in an order. The aim is to set up a connection between these problems that are seen independent from each other. This type of approach also means not to begin to solve the problems from what the therapist wants but the patient. A cognitive-behavioral oriented "Awareness Program” approach to decrease obese individuals’ depression level has been developed by researches. The effects of the cognitive-behavioral oriented awareness program on the depression level of obese individuals have been investigated in this study.

Based on this aim the following hypothesis has been tested: "The Awareness program based on the cognitivebehavioral approach principles has a significant effect in decreasing depression level of obese individuals”.

\section{Method}

\subsection{Participants}

During March 2012, this study as an awareness program for obese adults had been announced from a private psychiatry clinic in Samsun city of Turkey participated. A voluntary basis that individuals were weighed out and examined by a psychiatrist. Excluding criteria is having any severe neuropsychiatric disorder. Totally 20 participants included in the program and filled in Beck Depression Inventory and a personal information form. The control $(n=10)$ and the experimental groups $(n=10)$ were determined. In the experimental group, the age of the individuals are between $22-45(X=33.20, \mathrm{~s}=8.18)$, and their weights are between $84-106(X=92.20$, s = 7.33). In control group, their ages are between $23-44(X=34.10, s=8.19)$ and their weights are between 84-105 ( $\mathrm{X}=91.80, \mathrm{~s}=7.43)$. In each group there are 2 males and 8 females.

\subsection{Design of the Study}

In this empirical study which has been conducted in order to see the effects of an awareness program based on the cognitive-behavioral approach on the depression of obese individuals, pre-test and post-test control group have been used. The independent variable of the study is the awareness program and the dependent variable of the study is depression.

\subsection{Instruments}

The data necessary to investigate the effects of the developed program has been gathered by the Beck Depression Inventory. The Beck Depression Inventory was adapted to Turkish to measure depression level by N. Şahin Hisli [9]. It consists of 21 items. The validity and reliability of the scale was studied with 259 university students. The split-half reliability correlation score between two halves was 0.74 . The validity was studied by correlating the scale with the MMPI-D scale. Correlation coefficient between the two measures was found to be 0.63 . 


\subsection{Procedure and Data Analysis}

The Awareness Program consisted of 2-hour sessions on ten weeks. In the first session the Beck Depression Scale was given as pre-test and the Beck Depression Scale was given to the control group at the same time to the experimental group. In order to test the difference-whether it is meaningful or not-between the depression pre-test and the post-test of the control and the experimental group are stated on Table 1.

On Table 1, no meaningful difference is detected between the depression levels of both the control and the experimental group. The experimental group has attended to ten awareness sessions; whereas the control group has not been interfered during the same period. After ten weeks the Beck Depression Scale has given to the experimental and the control groups again as a post-test. The activities used in the sessions which are based on the cognitive-behavioral approach are given in Table 2.

Pre- and post test scores of control and experimental groups in The Beck Depression Scale were designed in such a way to test the hypothesis of the research, the Mann-Whitney U Test and Wilcoxon signed-rank test were conducted. The statistical analyses have been done by using SPSS program.

\section{Results}

"The awareness program based on cognitive-behavioral approach reduces the depression level of the obese individuals".

Mann Whitney U Test scores concerning post-test scores of the obese individuals are stated on Table 3.

Mann-Whitney $U$ test has been applied to the depression scores of the participants. The results of the Mann-Whitney U test indicate that the difference between the scores of the participants of the experimental and control groups in post tests in terms of level of depression is significant $(Z=-3188, p<0.01)$.

When the rank averages are taken into consideration, it is understood that the depression level of attendants is lower than the non-attendants to the study. This shows that the awareness program is effective in decreasing the depression level of the obese individuals.

Wilcoxon Signed Rank Test results are presented on Table 4 to see the whether there is difference between the pre-test and post-test scores of the individuals in experimental group.

Table 4. Wilcoxon Signed Rank Test results show that there is meaningful difference between the pre-test and post-test scores of the individuals in experimental group concerning their level of depression. When the rank total of difference scores is taken into consideration, it is seen that these scores are positive ranks and they are in favor of the post-test scores.

Whether there is meaningful difference between the pre-test and post-test scores of the control group individuals are tested via Wilcoxon Signed Rank Test and the result are stated on Table 5.

Table 1. Mann-Whitney U test result of the depression score in terms of pre-test.

\begin{tabular}{ccccccc}
\hline Group & $\mathrm{N}$ & Mean Rank & Sum of Rank & U & Z & P \\
\hline Experiment & 10 & 11.10 & 111.0 & 44 & -0.465 \\
Control & 10 & 9.90 & 99.00 & & 0.684 \\
\hline
\end{tabular}

$\mathrm{P}>0.05$.

Table 2. The activities of the awareness program.

\begin{tabular}{cr} 
Session & Activities \\
\hline I. & Group members meet each other. Discussing of group rules. Informing about obesity \\
II. & Informing about automatic thoughts and sharing automatic thoughts about obesity, feeding habits and body images. Homework. \\
III. & Informing about cognitive schemas and sharing their thoughts, feelings and behavior about cognitive schemas. Homework. \\
IV. & Informing irrational and rational thoughts. Relaxation exercises. Homework. \\
V. & Informing irrational and rational beliefs. Identification training about beliefs. Homework. \\
VI. & Disputing irrational and rational beliefs about obesity, homework. \\
VII. & Informing self help. Discussing of self help strategies. \\
VIII. & Informing changing cognitions. Changing cognitions exercises. Role play exercises about changing behavior. Homework. \\
IX. & Evaluation of the process. Sharing of opinions and emotions about the program. \\
X. &
\end{tabular}


Table 3. Mann-Whitney U test result of the depression score in terms of post-test.

\begin{tabular}{ccccccc}
\hline Group & $\mathrm{N}$ & Mean Rank & Sum of Rank & $\mathrm{U}$ & $\mathrm{Z}$ & $\mathrm{P}$ \\
\hline Experiment & 10 & 6.30 & 63 & 8 & -3188 & 0.001 \\
Control & 10 & 14.70 & 147 & & & \\
\hline
\end{tabular}

$\mathrm{P}<0.01$.

Table 4. Wilcoxon Signed Ranks test result of the experimental group in terms of post-test and pre-test.

\begin{tabular}{|c|c|c|c|c|c|c|}
\hline & & $\mathrm{N}$ & Mean Rank & Sum of Ranks & $\mathrm{Z}$ & $\mathrm{P}$ \\
\hline Post-test-Pre-test & $\begin{array}{c}\text { Negative Ranks } \\
\text { Positive Ranks } \\
\text { Equal }\end{array}$ & $\begin{array}{c}10 \mathrm{a} \\
0 \mathrm{~b} \\
10\end{array}$ & $\begin{array}{l}5.50 \\
0.00\end{array}$ & $\begin{array}{c}55.00 \\
0.00\end{array}$ & $-2.812 \mathrm{a}$ & 0.005 \\
\hline
\end{tabular}

$\mathrm{P}<0.05$

Table 5. Wilcoxon Signed Ranks test result of the control group in terms of post-test and pre-test.

\begin{tabular}{ccccccc}
\hline & & $\mathrm{N}$ & Mean Rank & Sum of Ranks & $\mathrm{Z}$ & \\
\hline \multirow{3}{*}{ Post-test-Pre-test } & Negative Ranks & 3a & 2.00 & 6.00 & $-1.732 \mathrm{a}$ \\
& Positive Ranks & Eq & .00 & .00 & .083 \\
\hline
\end{tabular}

$\mathrm{P}>0.05$.

The results of Wilcoxon Signed Rank Test on Table 5 show that there is no meaningful difference between the pre-test and post-test scores of the depression levels of the individuals in control group.

The results show that the awareness program based on Cognitive-Behavioral Approach reduces the level of depression of the obese individuals at a meaningful level. These results prove the hypothesis of this research.

\section{Conclusion}

The purpose of this study was to evaluate the effectiveness of awareness program based on cognitive-behavioral approach principles in decreasing the level of depression in obese individuals. Pre- and post-tests were given to the experimental and control groups. The program lasted ten weeks with experimental group. The results of the Mann-Whitney U test indicate the significant differences between the levels of depression of individuals on the experimental and control group. The number of participants was limited to ten people. This cognitive-behavioral oriented awareness program on depression decreased the depression level of individuals significantly. Some similar studies support the findings of our research [10]-[14]. As a result, depression should not be an exclusion criterion for weight loss intervention programs [15]. A meta-analysis confirmed a reciprocal relationship between depression and obesity [16]. Further prospective researches could be maintained to develop new cognitive and behavioral strategies for obesity and depression comorbidity.

\section{Role of the Funding Source}

The authors received no funding.

\section{Contributors}

All authors revised and approved the final form of the manuscript.

\section{Conflicts of Interest}

Authors declared no conflict interest.

\section{References}

[1] Hill, J.O. (1998) Dealing with Obesity as a Chronic Disease. Obesity Research, 6, 1-8. http://dx.doi.org/10.1002/j.1550-8528.1998.tb00686.x 
[2] Pi-Sunyer, F.X. (1998) NHLBI Obesity Education Initiative Expert Panel of the Identification, Evaluation, and Treatment of Overweight and Obesity in Adults-The Evidence Report. Obesity Research, 6, 51-209.

[3] World Health Organization (2000) Obesity: Prevention and Managing the Global Epidemic. WHO Obesity Technical Reports Series, 894.

[4] Kasen, S., Cohen, H. and Must, A. (2008) Obesity and Psychopathology in Women: A Three Decade Prospective Study. International Journal of Obesity, 32, 558-566. http://dx.doi.org/10.1038/sj.ijo.0803736

[5] Istvan, J., Zavela, K. and Weidner, G. (1992) Body Weight and Psychological Distress in NHANES I. International Journal of Obesity and Related Metabolic Disorders, 16, 999-1003.

[6] American Psychiatric Association (2000) Diagnostic and Statistical Manual of Mental Disorders. 4th Edition, Text Revision, Washington DC.

[7] De Zwaan, M., Mitchell, J.E., Seim, H.C., Specker, S.M., Pyle, R.L., Raymond, N.C., et al. (1993) Eating Related and General Psychopathology in Obese Females with Binge Eating Disorders. International Journal of Eating Disorders, 15, 45-52.

[8] Pratt, E.M., Telch, C.F., Labouvie, F.W., Wilson, G.T. and Agras, W.S. (2001) Perfectionism in Women with Binge Eating Disorder. International Journal of Eating Disorders, 29, 177-186. http://dx.doi.org/10.1002/1098-108X(200103)29:2<177::AID-EAT1007>3.0.CO;2-X

[9] Savaşır, I. and Şahin, N.H. (1997) Bilişsel-Davranışçı Terapilerde Değerlendirme: SıkKullanılan Ölçekler. Türk Psikologlar Derneği Yayınları, Ankara, 23-38.

[10] Wadden, A.T. and Foster, G.D. (2000) Behavioral Treatment of Obesity. Medical Clinics of North America, 84, 441461. http://dx.doi.org/10.1016/S0025-7125(05)70230-3

[11] Cooper, Z. and Fairburn, C.G. (2001) A New Cognitive Behavioral Approach to the Treatment of Obesity. Behaviour Research and Therapy, 39, 499-511. http://dx.doi.org/10.1016/S0005-7967(00)00065-6

[12] Cooper, Z. and Fairburn, C.G. (2002) Cognitive Behavioral Treatment of Obesity. In: Wadden, T.A. and Stunkord, A.J., Eds., Handbook of Obesity Treatment, New York, 465-479.

[13] Fabricatore, A.N. (2007) Behavior Therapy and Cognitive-Behavioral Therapy of Obesity: Is There a Difference. Journal of the American Dietetic Association, 107, 92-99. http://dx.doi.org/10.1016/j.jada.2006.10.005

[14] Corbalon, M.D. and Morales, M.E. (2009) Effectiveness of Cognitive-Behavioral Therapy Based on the Mediterranean Diet for the Treatment of Obesity. Nutrition, 25, 861-869.

[15] Ludman, E., Simon, G.E., Ichikawa, L.E., Operskalski, B.H., Arterburn, D., Linde, J.A., Jeffery, R.W., Rohde, P. and Finch, E.A. (2010) Does Depression Reduce the Effectiveness of Behavioral Weight Loss Treatment? Behavioral Medicine, 35, 126-134. http://dx.doi.org/10.1080/08964280903334527

[16] Luppino, F.S., de Wit, L.M., Bouvy, P.F., Stijnen, T., Cuijpers, P., Penninx, B.W.J.H. and Zitman, F.G. (2010) Overweight, Obesity, and Depression-A Systematic Review and Meta-analysis of Longitudinal Studies. Archives of General Psychiatry, 67, 220-229. http://dx.doi.org/10.1001/archgenpsychiatry.2010.2 